\title{
Quality Improvement by Preliminary Action through the Semiconductor Wire Bonding Process TRIZ
}

\section{반도체 와이어 본딩 공정 트리즈를 통한 예비작용에 의한 품질향상}

Kwang Jun Lee ${ }^{1}$, Yong Won Song ${ }^{2}$, Hong Kyun Shim ${ }^{3}$, Sang Ook Jun ${ }^{4}$, Chan Ho Park ${ }^{5}$

이광준 ${ }^{1}$, 송용원 ${ }^{2}$, 심홍균 $^{3}$, 전상욱 ${ }^{4}$, 박찬호 $^{5}$

${ }^{1}$ Engineer, SK Hynix semiconductor Co., Ltd, South Korea, gwangjun.lee@sk.com

${ }^{2}$ Professor, Department of Nano Semiconductor Engineering, Korea Polytechnic University, South Korea, ywsong@kpu.ac.kr

${ }^{3}$ Engineer, SK Hynix semiconductor Co., Ltd, South Korea, hongkyun.shim@sk.com

${ }^{4}$ Engineer, SK Hynix semiconductor Co., Ltd, South Korea, sangook.jun@sk.com

${ }^{5}$ Engineer, SK Hynix semiconductor Co., Ltd, South Korea, chanho2.park@sk.com

Corresponding author: Yong Won Song

\begin{abstract}
Since the 4th industrial revolution has progressed, all technologies in the world have continued to develop. Among them, the semiconductor industry is an ultra-high-density technology, and technology development is underway to increase the degree of integration in order to produce fine, highquality products. In this paper, a method for increasing the degree of integration of wire bonding in the packaging process and improving the quality was studied. By introducing TRIZ specialized in problemsolving method, the problem of the 2 nd bond was confirmed. analysis was carried out. As an analysis technique, a preliminary action was applied using micro-level microanalysis and internal resources to resolve the contradiction in which two situations conflict by using the contradiction resolution and the small person model. The reduction of defects and improvement of bonding strength through the first preliminary action attempted in the wire bonding process can be confirmed through this paper.
\end{abstract}

Keywords: Wire Bond, TRIZ, Bump, Stitch Bond, BPT

요약: 18 세기 초 산업혁명 이후 4차 주요 산업인 디지털산업의 발전으로 인하여 세상의 모든 기술은 인공지능 및 사물인터넷 등의 융합을 통해 발전을 거듭하고 있다. 그중 초 고밀도 기술인 반도체 산업은 미세한 고품질의 제품을 생산하기 위해 집적도를 높이는 기술개발을 진행하고 있다. 본 논문에서는 Packaging(패키징) 공정의 와이어 본딩의 집적도를 높이고 품질 향상을 위한 방법을 연구하였다. 문제 해결 방법에 특화된 TRIZ를 도입하여 2nd Bond (두 번째 접합)에 대한 문제점에 대해서 확인하였고 이를 토대로 구조적 개선인 $\mathrm{Bump}($ 범프) + Stitch $\operatorname{Bond}($ 접합)의 획기적인 방법을 적용하여 접합력의 상관관계에 대해서 분석을 실시 하였다. 분석 기법으로는 모순 해결과 작은사람 모델을 활용하여 두가지 상황이 상충되는 모순을 해결하고자 마이크로 레벨 수준의 미세 분석과 내부 자원을 활용하여 예비작용을 적용하였다. 와이어 본딩 공정에서 시도된 첫 예비작용을 통한 불량 감소와 접합력 향상에 대해서 본

Received: June 13, 2021; $1^{\text {st }}$ Review Result: July 28, 2021; $2^{\text {nd }}$ Review Result: September 12, 2021 Accepted: October 31, 2021 
논문을 통하여 확인할 수 있다.

핵심어: 와이어 본드, 트리즈, 범프, 스티치 본드, 본드 풀 테스트

\section{1. 서론}

디지털 혁명에 기반하여 반도체는 더욱 집적도가 매우 높아지고 있다. 특히 반도체 산업의 특성에 따라서 다품종 소량생산에 대한 제품의 고도화, 초소형화가 이루어지고 있으며, 반도체의 고도화[1] 에 따른 처리속도의 향상은 수율 저하로 이어지고 있다. 이로 인한 반도체 품질의 향상은 생산성 향상과 함께 매누 중요한 기준이다. 반도체의 제조공정은 다음과 같이 8 대 공정으로 Wafer 제조, 산화, 포토, 식각, 증착 및 이온 주입, 금속 배선, Electrical die Sorting(EDS), Packaging 으로 구분된다[2]. 본 논문은 반도체 8대 공정 중 Packaging 공정의 와이어 본딩[3] 품질 향상을 위하여 TRIZ를 활용한 연구사례이다.

\section{1 와이어 본딩(Wire Bonding)}

반도체 전(前)공정을 마친 웨이퍼에는 장당 수백 수천 개의 칩이 생산된다. 생산된 반도체 칩을 생산하기 위해서는 웨이퍼 안의 칩을 개별 칩으로 나누는 Sawing 공정을 진행하게 된다. 개별 칩과 회로 기판의 전기적인 도통 상태를 만들기 위해서 고순도 골드와이어(이하 골드와이어로 표기)로 연결한다. 이때 전기적 신호의 통로인 도선을 연결하는 공정이 바로 와이어 본딩이다. 와이어 본딩은 머리카락보다 얇은 골드와이어(Gold Wire)를 반도체 칩인 패드에 접합 시켜 반도체 내부의 칩과 외부인 기판을 연결하는 기술이다. 구조적 측면의 골드와이어는 반도체 칩의 본딩 패드(1차 본딩)와 기판 리드의 도선(2차 본딩)을 연결하는 역할을 하는 것이다. 와이어 본딩 공정 초기에는 리드프레임(Lead Frame) 재질을 사용하여 도선을 연결 하였으나, 기술이 발전하여 현재는 $\mathrm{PCB}$ (기판)를 사용하고 있다. 물리적으로 떨어져 있는 2 개의 패드와 리드를 연결하는 와이어 본딩은 도선을 연결하기 위한 골드와이어의 재질과 구조적 조건, 그리고 접합하는 위치(칩과 기판 사이가 아닌 칩과 칩 사이 또는 기판과 기판 사이를 도선으로 연결하는 구조도 존재함) 등이 매우 다양하다. 와이어 본딩을 작업하기 위한 가장 핵심적인 장치는 캐피러리(Capillary)로, 여러 연결방식이 있지만 주로 골드와이어를 적용한다. 골드와이어를 사용하는 이유는 전류의 흐름이 좋고 안정적으로 유지되어 부식에 강하다. 또한 골드와이어는 루프궤적 형성 시 경도가 적당하여 1 차 본딩 시 IMC(Inter Metal Compound)가 잘 형성되며, 2차 본딩 시 Stitch가 반원 형태로 알맞게 형성된다[그림 1].

와이어 본딩 공정에서 가장 많이 사용하는 접합 방식은 열을 이용한 열 압착 방식과 초음파를 추가한 열 초음파(Thermersonic) 방식으로 캐피러리에 압력, 초음파를 열이 가해진 $\mathrm{PCB}$ 위에 Bonding을 진행하게 된다. 와이어 본딩 공정의 Bonding을 위해서는 캐피러리를 사용하여 접합을 진행한다. 캐피러리는 와이어 본딩에서 사용되는 캐피러리의 구조, 크기에 따라서 접합 면적, 접합 강도의 차이가 발생하게 된다. 이 접합력 향상은 BPT(Bond Pull Test)[4], BST(Bond Share Test)[5]를 통하여 수치화 할 수 있다. 해당 값들은 실제 접착된 골드와이어의 접합 강도와 인장 강도로 표현되며, 캐피러리와 
골드와이어의 접합을 진행한다. 구조적 다단형태의 제품 작업 시 좁은 $\operatorname{Lead(ㄷㅏㄹㅣ)ㅇㅘ~}$ Stitch Bond(접합)사이에 약한 접합력이 형성되어 접합되지 않는 형태(미접합)의 불량이 발생하여 해당 미 접합에 대한 개선이 필요하며, Stitch Bond의 접합력인 인장 강도는 신뢰할 수 있는 수준의 Data 확보가 필요하다.

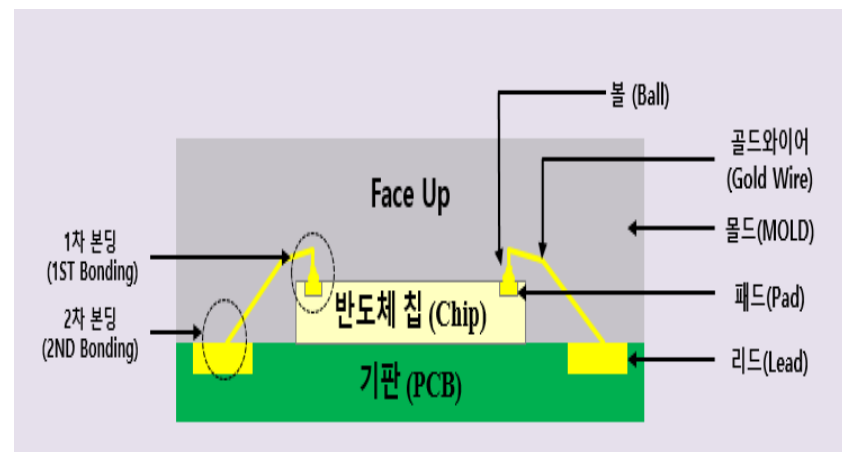

[그림 1] 와이어 본딩 구조

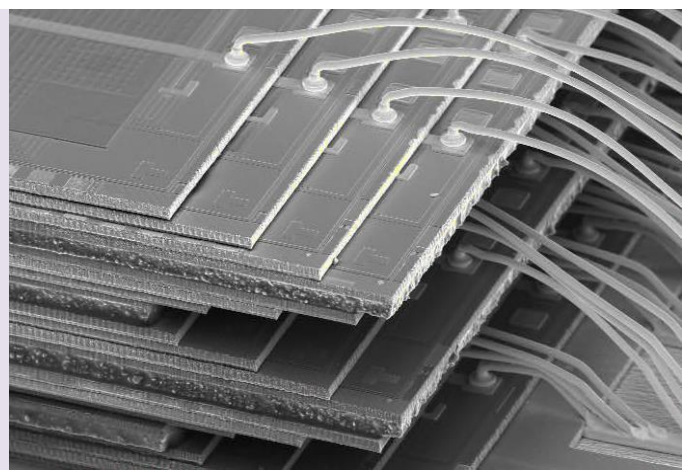

[Fig. 2] Wire Bonding Structure

\subsection{TRIZ (Theory of Solving Inventive Problem)}

창의적 문제해결 이론인 트리즈(Theory of Inventive Problem Solving, TRIZ)는 러시아의 발명가 겐리히 알츠슐러(Genrich Altshuller)가 러시아 특허청에 등록된 특허들중 150 만 건에서 4 만 건의 특허를 분석하여 문제해결 수준에 따라 5단계로 나누고, 그 중 3-5 수준의 문제를 분석하여 문제해결의 분석을 통한 공통 원리를 추출하여 정립한 이론이다[6][7]. TRIZ는 문제해결에 있어 체계적인 접근 방법을 제공하며, 문제해결 Solution을 과학적이며 논리적으로 접근하도록 도와주는 이론이다. 본 논문에서는 TRIZ의 여러 문제분석을 위한 도구 중 기능 분석, 물질-장 분석 및 인과 관계 분석을 이용하며, 문제 해결을 위하여 40 가지 발명원리, 공간 분리 및 표준해를 사용하였다. 그리고 물리적 모순 분석을 활용하여 문제 해결을 진행하였으며, 다양한 측면에서 얻어진 해결안을 분석/통합하여 최종 아이디어를 도출하였다.

\section{2. 와이어 본딩 품질 검증}

\section{1 와이어 본딩 품질 검증}

개별 칩 간 골드와이어의 접합력을 확인하기 위해서는 특정 Tip을 이용하여 측면에서 전단력(Shear Force)을 가하여 다음과 같이 접합력(Bond Ability)을 확인한다. 첫 번째 Bond의 접합력은 BST(Ball Shear Test)를 진행하여 접합력을 확인한다. 테스트 방법으로는 반도체의 패드와 골드와이어의 접합력을 확인하기 위하여 PAD Bonding된 Ball을 특수재질 $\mathrm{TIP}$ 을 이용하여 밀어내는 파괴 검사 방식으로 진행하며 측정값은 $1 \mathrm{~g}$ 단위로 측정한다[그림 2]. 


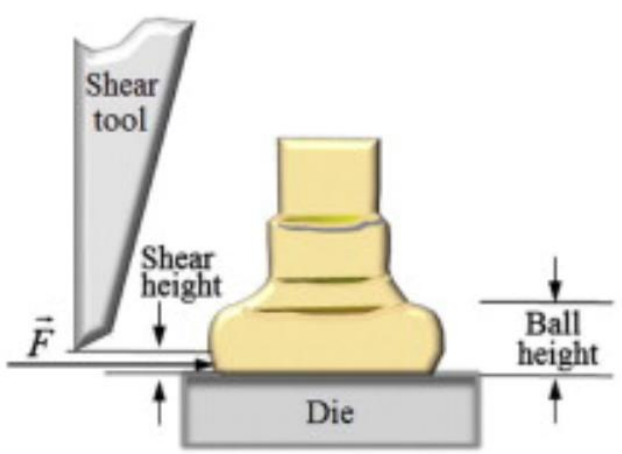

[그림 2] Bond Shear Test기준

[Fig. 2] Bond Shear Test Standard

$\mathrm{BST}$ 측정 결과에 따라 확인하는 요인은 다음과 같으며[표 1] 파단된 Test에서 Ball Shear Test Mode 따라서 접합력과 관계없이 불량으로 확인하고 있다. 특정 Fail Mode는 아래 항목으로 Mode와 형태에 따라서 접합력을 확인하는 데 있어 중요한 참고 항목이다.

[표 1] Ball Shear 평가 모드

[Table 2] Ball Shear Test mode

\begin{tabular}{|c|c|}
\hline Mode & Break position \\
\hline 1 & Ball이 Band pad로부터 완전히 떨어지는 양상. 잔류되는 Ballo 이 Bond pad에 없음 \\
\hline 2 & Ball 중간이 절단되면서 shear 되는경우 \\
\hline 3 & Pad Ball이 Pad와 함께 절단되는 경우 \\
\hline 4 & Oxide damage 또는 Silicon damage가 발생되는 경우 \\
\hline
\end{tabular}

기판의 리드와 골드와이어의 접합력을 확인하기 위해서는 다음과 같은 방법으로 접합력 (Bond Ability)를 확인한다. 두 번째 Bond (Stitch Bond)의 접합력을 확인하기 위해서는 BPT(Bond Pull Test)를 진행한다. BPT는 두 번째 Bond (Stitch Bond)의 접합력을 결정하는 방법으로 일반적으로 Bonding 된 골드와이어의 Loop 최고점에서 특수한 재질의 Hook 형태를 사용하여 골드와이어를 당기고 측정된 값을 결정한다[그림 3].

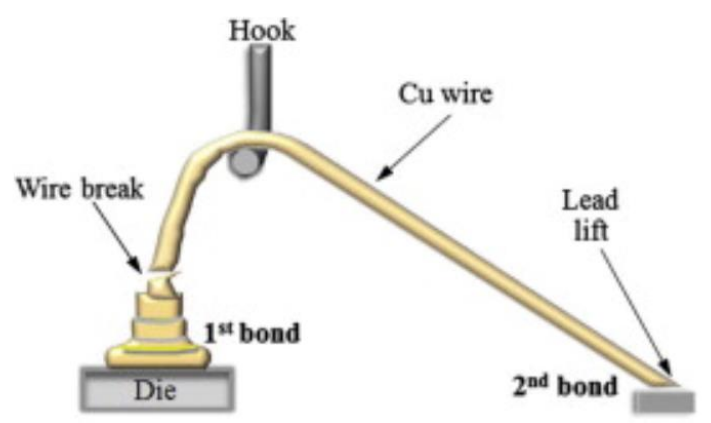

[그림 3] Bond Pull 평가 기준

[Fig. 3] Bond Pull Test Standard

와이어 본딩에서 사용되는 BPT의 규정은 다음과 같으며, Bond Pull Test Mode에 따라서 
양품과 불량으로 구분하여 제품에 대한 신뢰성을 높이고 있다. 해당 내용은 $\mathrm{BPT}$ 를 측정한 이후 측정된 Mode와 형태에 따라서 두 번째 Bond 접합력에 어떠한 영향을 미치고 있는지 참고해야 할 주요 항목이다[표 2].

[표 3] Bond Pull 평가 모드

[Table 4] Bond Pull Test Mode

\begin{tabular}{|c|c|}
\hline Mode & Break position \\
\hline 1 & PAD Ball beck 위치에서 골드와이어가 끊어지는 경우 \\
\hline 2 & Bond Stitch neck 부분에서 골드와이어가 끊어지는 경우 \\
\hline 3 & Bond Pad로부터 골드와이어 PAD Ball이 완전히 분리되는 경우 \\
\hline 4 & Stitch 2nd bond가 완전히 분리되는 경우 \\
\hline 5 & Bond neck 부분 또는 Loop 중간에서 골드와이어가 끊어지는 경우 \\
\hline 6 & Bond pad 메탈부분이 들뜨는 경우 \\
\hline 7 & Post Bond에서 Plating 된 부분이 끊어지는 경우 \\
\hline
\end{tabular}

와이어 본딩 공정에서의 주요 Parameter와 주요 기능에 대한 내용에 대해서 아래와 같이 규정하도록 되어있다. 주요 기능에 대한 세부적인 항목들은 다음과 같다. 반도체 제품의 고도화에 따른 다단 구족의 형태가 늘어남에 따라서 $1 \mathrm{ST}$ Stitch와 $2 \mathrm{ND}$ Stitch로 구분하여 표현하였다. 이는 동일 기판의 리드에 접합하는 구조로 설명할 수 있다[표 3].

[표 5] 주요기능 구성요소 분석

[Table 6] Analysis of Major Functional Components

\begin{tabular}{|c|c|}
\hline Mode & Break position \\
\hline Bond Forcd & 캐피러리 표면에 작용하는 압력 \\
\hline Bond USG & 캐피러리 표면에 적용하는 초음파(Ultrasonic Generator) \\
\hline Bond Time & 캐피러리에 압력과 초음파가 적용되는 시간 \\
\hline Loop & 장비에서 캐필러리를 통해 골드와이어의 궤적을 만드는 이동경로 \\
\hline 캐피러리 & $\begin{array}{c}\text { 매우 얇은 골드와이어를 접합 또는 결속시키기 위한 바늘과 콘 모양으로 루비 또는 } \\
\text { 세라믹으로 구성 }\end{array}$ \\
\hline 고순도 골드와이어 & $\begin{array}{c}18 \mu \mathrm{m} \text { 의 머리카락 보다 얇은 골드와이어로 금 함유량이 } 99.99 \% \text { 의 매우 높은 순도를 } \\
\text { 사용 }\end{array}$ \\
\hline Wire Clamp & 골드와이어를 지지하거나 결속이 완료된 골드와이어를 잡아주어 고정함 \\
\hline 히터블럭 & 기판을 고정하여 열을 전달하는 기구 \\
\hline $\begin{array}{l}1 \text { st 본드 } \\
\text { (반도체 칩 결속) }\end{array}$ & Bond Force / Bond USG / Bond Time을 가하여 골드와이어를 Bond Pad에 접합 \\
\hline $\begin{array}{l}\text { 2nd 본드 } \\
\text { (기판 결속) }\end{array}$ & Bond Force / Bond USG / Bond Time을 가하여 골드와이어를 Bond Lead에 접합 \\
\hline $\begin{array}{c}\text { 1st Stitch } \\
\text { (첫 번째 기판 결속) }\end{array}$ & Bond Lead에 첫 번째 접합 후 발생되는 흔적 \\
\hline $\begin{array}{l}\text { 2nd Stitch } \\
\text { (두 번째 기판 결속) }\end{array}$ & Bond Lead에 두번째 접합 후 발생되는 흔적 \\
\hline
\end{tabular}




\section{2 규제 및 제약조건}

다단 구조의 패키지를 작업하는 과정에서 접합력의 저하로 인한 미 접합이 발생하여 품질 불량이 발생하는 문제를 개선하기 위한 규제 및 제약조건으로 반도체 칩과 기판의 접합 면적은 현재 형태를 고정으로 유지하도록 설계되어 있다. 이는 생산된 반도체 칩의 구조와 설계가 사전에 반영되어 있어 변경을 금지한다. 캐피러리의 디자인은 회사 내부 지침에 따라서 고정형태를 유지하도록 하였다. 접합력 향상을 위해서는 접합 면의 크기가 넓어야 하며, 캐피러리의 크기는 작아야 하는 물리모순이 발생한다. 현재 구조를 변경하지 않는 수준에서 접합력이 개선되는 방향으로 개선을 진행하는 것을 원칙으로 검증하였다. 접합력 향상을 위한 평가는 모든 Data의 정합성을 위하여 고정 설비에서만 평가를 진행 하였으며, 해당 내용을 기반으로 검증하도록 제약하였다.

\section{TRIZ를 활용한 문제분석}

\section{1 시스템적 기능분석}

문제 상황에 대한 세밀한 분석을 위해 TRIZ의 문제분석 방법인 System 기능 분석을 진행하였다. System 기능분석은 시스템 구성요소를 분석진행 하고 관련 부품들에 대한 상호 연관 관계 분석을 통하여 문제점을 정확하고 빠르게 확인할 수 있도록 하는 기법이다[8]. 현재 문제를 다양한 시각으로 분석하기 위하여 9 Window를 통하여 현재의 시스템을 중심으로 상위시스템과 하위시스템을 분석하고, 분석한 시스템의 과거의 모습과 이를 통한 미래의 발전 방향을 예측하는 방법이다. 와이어 본딩 공정에서의 현재의 시스템을 기준으로 9 Window 분석을 진행하였다[그림 4].

\section{9-Windows}

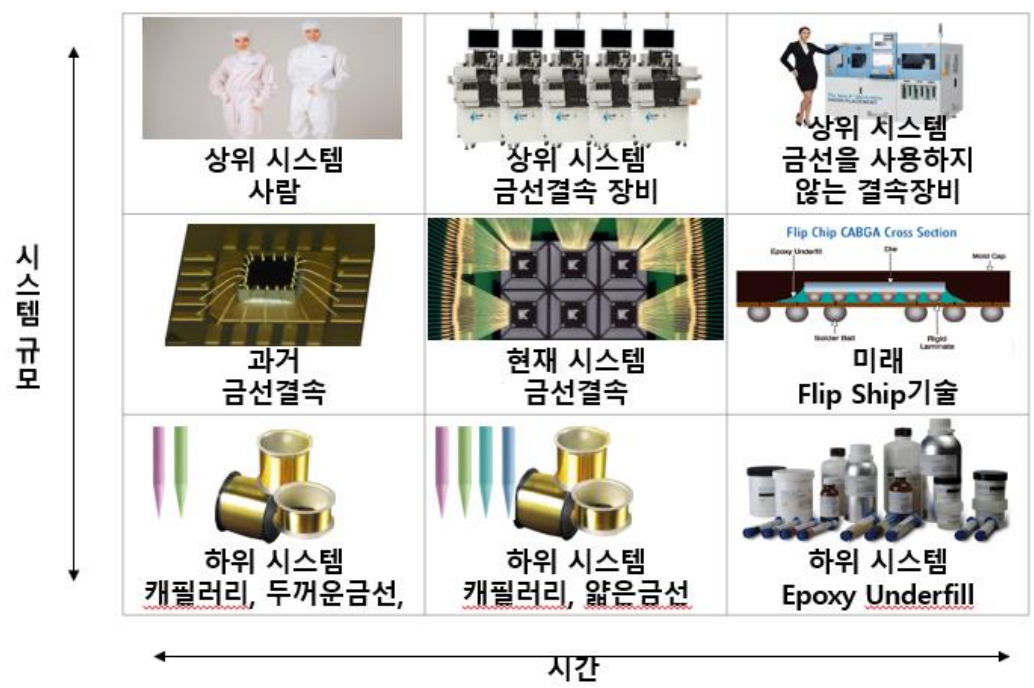

[그림 4] 9 Window 분석

[Fig. 4] 9 Window Analysis

와이어 본딩 공정에서 사용되는 주요 기능에 관한 내용과 Parameter에 대해 구성요소 분석을 진행하였다. $2 \mathrm{ND}$ Stitch 형성과 관련하여 모든 동작 구간을 프로세스 구성도를 
통하여 단계별로 작성하였으며, 각 항목에 대해서 유익작용, 약한 유익작용, 유해작용으로 분류하였다. 캐피러리는 하중과 초음파를 골드와이어에 전달하여 접합을 진행한다. 다단 칩의 경우 위와 같은 행위를 칩과 본딩 리드에 반복하여 접합하는 과정을 가지게 된다. 캐피러리(도구)는 두 번째 골드와이어를 본딩리드(대상)과 접합하기 위한 하중, 초음파가 약한 유익작용을 할 수 있음을 확인하였다. 두 번째 접합을 진행하는 과정에서 캐피러리(도구)는 본딩리드(대상)에 골드와이어를 접합하는 과정에서 첫 번째 골드와이어와 두 번째 골드와이어 간에 유해작용을 주는 것을 확인하였다[그림 $5]$.

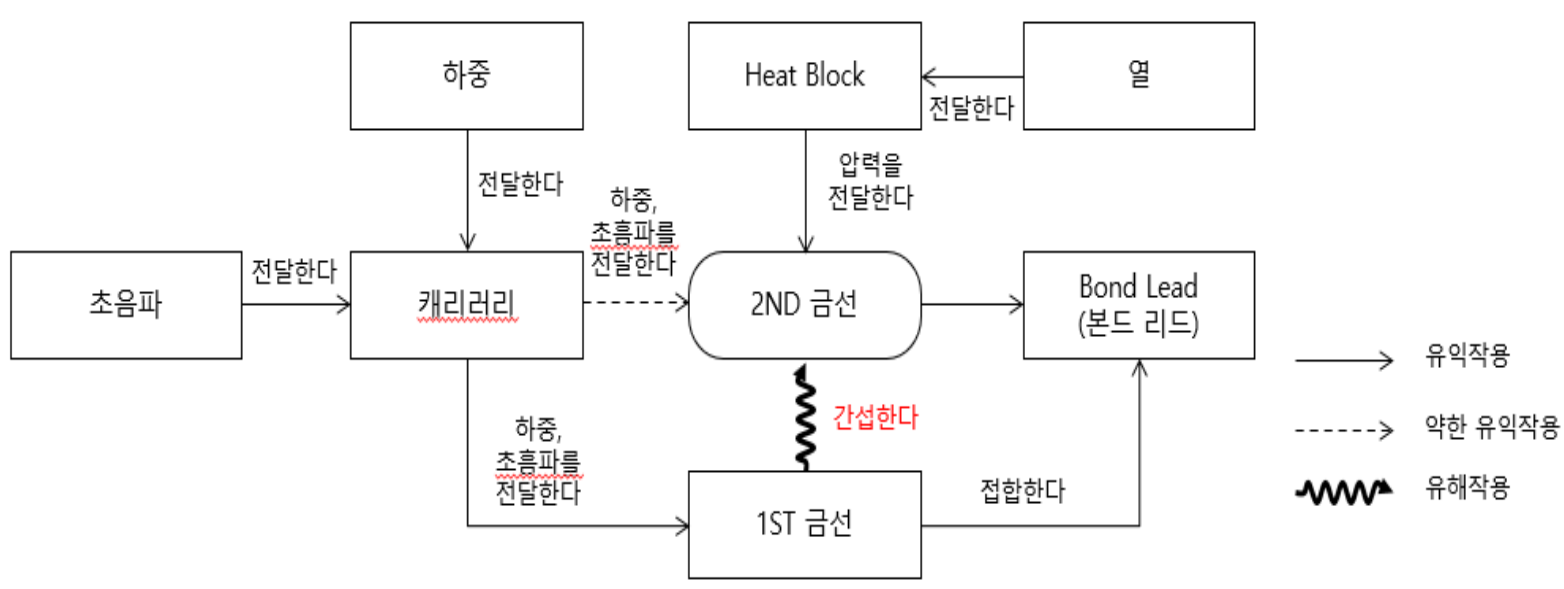

[그림 5] 상호 연관관계 분석

[Fig. 5] Correlation Analysis

\section{2 인과관계 분석 (Caust-Effect Chain Analysis : CECA 분석)}

와이어 본딩 공정에서 골드와이어를 반도체 기판에 결속하는 동작시 기 작업 된 첫 번째 작업 $1 \mathrm{ST}$ Stitch와 두번째 작업 $2 \mathrm{ND} \mathrm{Stitch}$ 와의 강한 간섭이 발생하여 접합력이 저하되는 문제가 발생하었다. 골드와이어의 궤적 형성 과정을 세밀하게 분석하게 위해 TRIZ 문제 분석 도구인 인과관계 분석 (Cause-effect chain analysis : CECA 분석)을 실시하였다. (Fig. 5) CECA 분석은 여러 원인이 있는 다중성 문제를 체계적으로 세밀하게 분석하는 방법이다. 인과 관계에 있어 해로운 작용이 발생하는 시간 Operation Time (OT)과 문제 발생 영역인 Operation Zone $(\mathrm{OZ})$ 을 분석하여 문제 해결방법에 더 쉽고 정확하게 도달 할 수 있도록 도와주고 있다[9]. 두 번째 접합을 형성하는 과정을 세부적으로 나누면 두 번째 본딩은 $2 \mathrm{ND} \mathrm{Stitch로} \mathrm{구분할} \mathrm{수} \mathrm{있다.} 2 \mathrm{ND}$ Stitch의 형성이 좋을수록 $\mathrm{BPT}$ 가 향상되지만, 구조적 다단구조에서 첫 번째 골드와이어와 간섭이 발생하게 되어 골드와이어간 접촉이 발생된다. 골드와이어 간 접촉이 발생하는 시점을 $\mathrm{OZ}$ 과 $\mathrm{OT}$ 로 정의하고, 골드와이어 간 간섭에 의한 접합력 저하로 미접합 불량이 발생하여 품질 수준을 저하하는 문제점을 확인할 수 있다[그림 6]. 


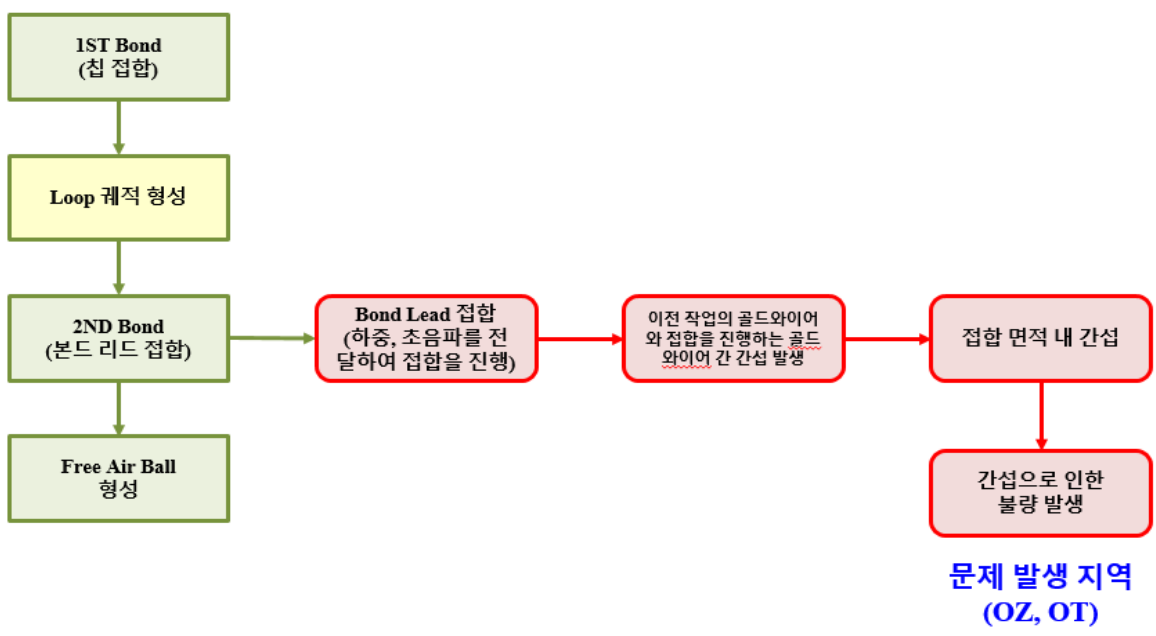

[그림 6] CECA 분석

[Fig. 6] CECA Analysis

\section{3 작은 사람 모델 분석}

확인된 문제에 대해 깊이 있는 세밀한 시점에서 확인을 하기 위해서는 작은 사람 모델 분석을 실시한다. 작은 사람 모델 분석은 세밀한 시점에서 문제 대상의 일부가 된 것처럼 미세하게 의인화하여 유추하는 기법이다[10]. 작은사람모델 분석을 통해 두 번째 접합을 위한 캐피러리가 하강하는 동작 중 첫 번째 Bond가 완료된 골드와이어와 두 번째 접합하는 골드와이어 간 미세한 간섭이 발생하는 것을 확인하였다. 또한 첫 번째 골드와이어와의 간섭으로 인하여 본드 리드로 전달해야 하는 하중, 초음파가 전이되어 실제 전달하고자 하는 하중, 초음파가 불충분하게 전달되는 약한 유익작용으로 접합력이 저하되어 미 접합이 발생하는 것을 확인하였다. 미 접합이 발생하면 두 번째 본딩의 Stitch가 제대로 형성되지 않아 품질 불량이 발생한다[그림 7].

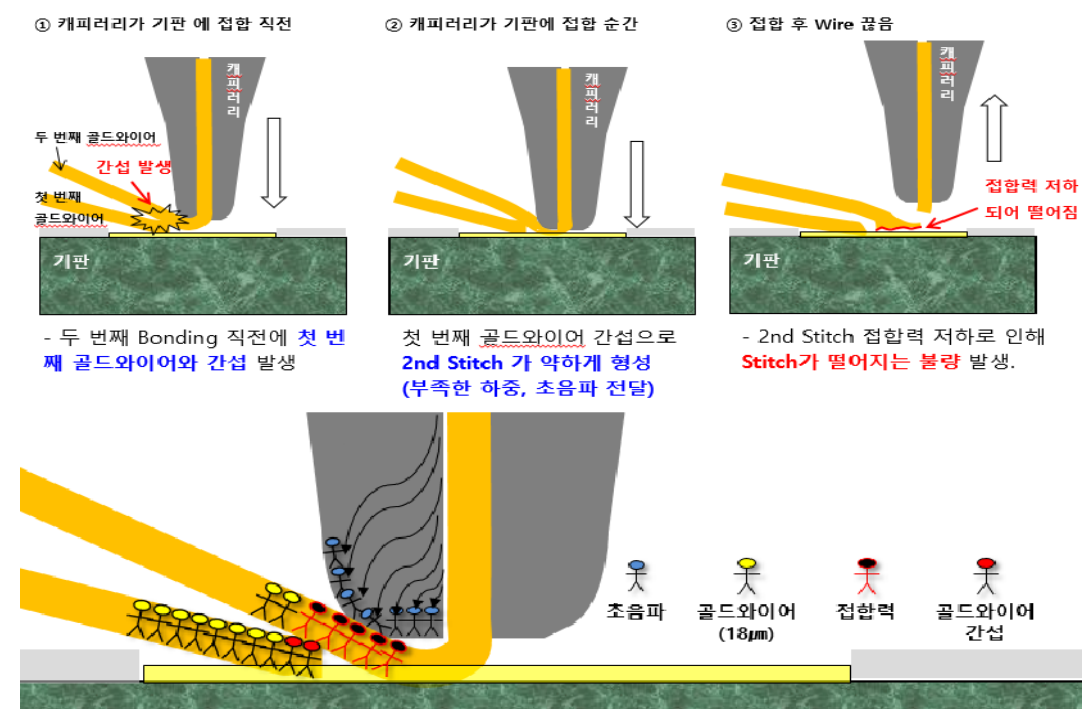

[그림 7] 작은사람 모델 분석

[Fig. 7] little Person Model Analysis 
캐피러리가 $2 \mathrm{ND}$ Stitch Bond를 진행하는 과정에서 골드 와이어간 간섭되는 부위를 확인하였으며, 캐피러리의 크기가 크면 접합력이 나빠지게 되어 품질이 저하되지만 캐피러리의 크기가 작으면 접촉면이 작아 품질이 좋아짐을 확인하였다. 또한 접합 면의 크기가 크면 큰 접합 면으로 인해 캐피러리의 간섭이 발생하지 않아 접합력이 좋아지지만 접합 면의 크기가 작아 좁아진 접합 면에서 간섭이 발생하여 품질이 저하되는 부분을 확인하였다. 접합 면의 크기는 넓을수록 안정적인 접합으로 인해 품질이 향상되며, 캐피러리는 외경이 작을수록 접합력이 저하되어 품질이 나빠지는 물리모순을 확인하였다. 확인된 모순은 제약조건에 의하여 현재 구조를 변경하지 못하지만 향후 개발되는 제품들에 대한 방향성을 참조 할 수 있다. 이와 같은 방식에서 접합 면을 보는 현재의 방식에서는 맨눈으로 확인이 불가한 문제를 마이크로 레벨에서 분석은 진행하여 실제 골드와이어 간의 간섭이 어떤 방식으로 이루어지는지에 대한 매우 의미 있는 분석이 진행되었으며, 이러한 모순에 대해서 정확한 고찰이 진행되었다[그림 8].
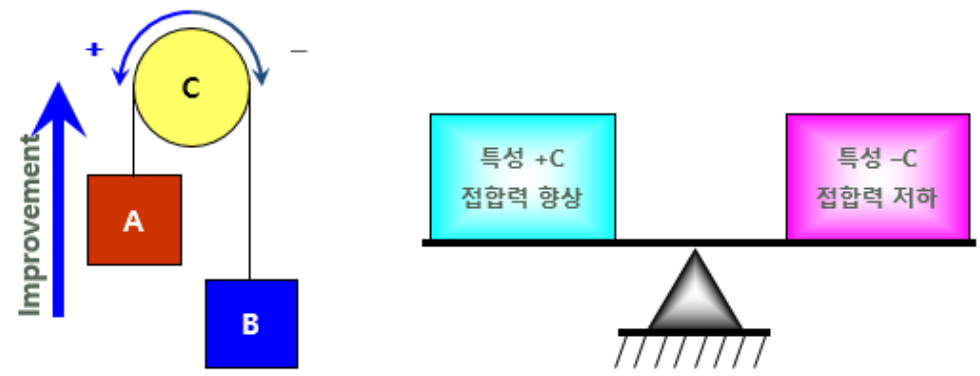

[그림 8] 물리적 모순 정의

[Fig. 8] Physical Contradiction Definition

접합력을 향상하기 위해서는 캐피러리 외경은 커야 하고 와이어 간 간섭을 막기 위해서는 캐피러리 외경은 작아야 한다. 하지만 물리적 모순을 해결하기 위해서는 $\mathrm{PCB}$ 의 Design을 변경하지 못하는 제약조건에 의하여 해결하기 어려운 문제로 판단된다. 신규 제품을 개발하는 방안에는 해당 물리적 모순을 개선하여 적용하는 방향으로 개발을 진행하도록 적용하였다.

\section{4. 문제 해결}

\section{1 이상적 해결안}

본 논문에서는 트리즈의 기법을 여러 기법을 적용하여 가장 이상적인 해결안을 제시하였으며, 채택된 제시안에 대해서는 Data 검증을 위하여 JUMP를 활용하여 검증을 진행하였다. 이상적 최종 해결안 IFR은 "2 ND Stitch 형성 시 접합 면의 크기는 골드와이어와의 간섭이 발생하지 않도록 넓어야 하며, 캐피러리의 면적은 골드와이어의 간섭이 없도록 작아야 한다.”라고 정의하였다. IFR은 현재 구조에서는 해결할 수 없는 문제로 물리적 모순을 해결하기 위해서는 시간 분리, 공간 분리, 조건 분리, 부분과 전체 분리 4 가지의 방법을 사용하여 해결안을 찾을 수 있다. 


\subsection{1 모순을 이용한 발명원리 아이디어}

모순이란 하나의 시스템안에서 한가지 특성을 개선했을 때 동시에 다른 특성이 나빠지거나 동시에 새로운 문제가 발생하는 매우 어려운 문제를 의미한다[11]. 현 상황의 모순은 "Stitch 형성을 위해 본딩리드 간격은 좁아야 하고 간섭을 일으키지 않기 위해 본딩리드 간격은 넓어야 한다"로 정의할 수 있다. $\mathrm{PCB}$ 의 Design을 변경하지 못하는 제약조건에 따라 사용 가능한 자원 안에서 아이디어를 도출하였다. 모순에서 정의한 대로 공간 분리를 이용하여 골드 와이어 간 간섭이 발생하지 않는 새로운 예비작용을 추가하는 방법으로 예비작용을 이용한 공간 분리를 진행하였다. $X$ 축에서는 Stitch 간격을 좁게 하고 Z축에서는 Stitch 간격을 높게 하는 것으로 해결안을 도출하였다. 일반화를 통한 내부 자원인 골드와이어를 이용하여 예비작용을 진행하여 높아진 Z축 공간으로 인해 첫 번째 골드와이어와 두 번째 골드와이어의 간섭이 발생하지 않고 골드와이어와 Stitch는 골드와이어 간 접합으로 접합력이 좋아지는 장점이 있다. 해당 모순을 공간 분리의 개념을 적용하여 해결안을 도출하였다[그림 9].

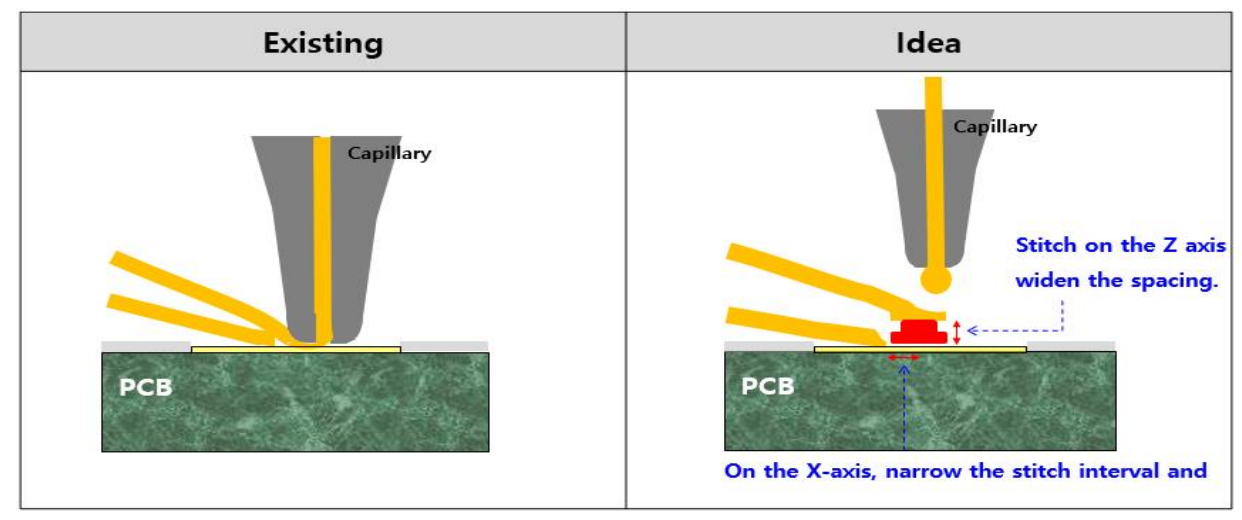

[그림 9] 기술적 모순

[Fig. 9] Technical Contradiction

\subsection{2 물질-장 분석을 이용한 표준해}

TRIZ의 이론에 따르면 모든 복잡한 문제는 대부분 모순의 형태를 가지고 있으며, 이러한 모순은 발명원리와 분리원리를 이용하여 창의적으로 해결할 수 있다. 그러나 모순의 형태를 가지고 있지 않거나, 또는 모순을 찾기 어려운 경우는 물질-장 분석을 진행하고 표준해를 활용하여 문제를 해결한다. TRIZ의 물질-장 분석은 두가지 물질과 그 사이에 작용하는 장(Field)을 분석하여 유익한 / 유해한 관계, 그리고 부족한 관계를 찾아 문제를 해결하는 분석기법이다. 이러한 문제 형태에 따라 추가되는 물질을 효과적으로 도입하여 문제 해결을 위한 해결안을 찾는 매우 체계적인 방법이다. 현재의 문제는 기계장을 이용하여 강한 하중을 적용하여 좁은 접합 면에서 골드와이어 간 간섭을 받아 골드와이어를 접합하는 부족한 작용이 발생한 것이다. 표준해 아이디어를 적용해 추가로 열 장을 이용하여 Heat Block에 전달하는 높은 열을 이용해 본딩리드에 과도한 유익 기능인 열을 전도 시켜 골드와이어의 접합력을 높이는 2 가지 방안을 찾을 수 있었다[그림 10]. 

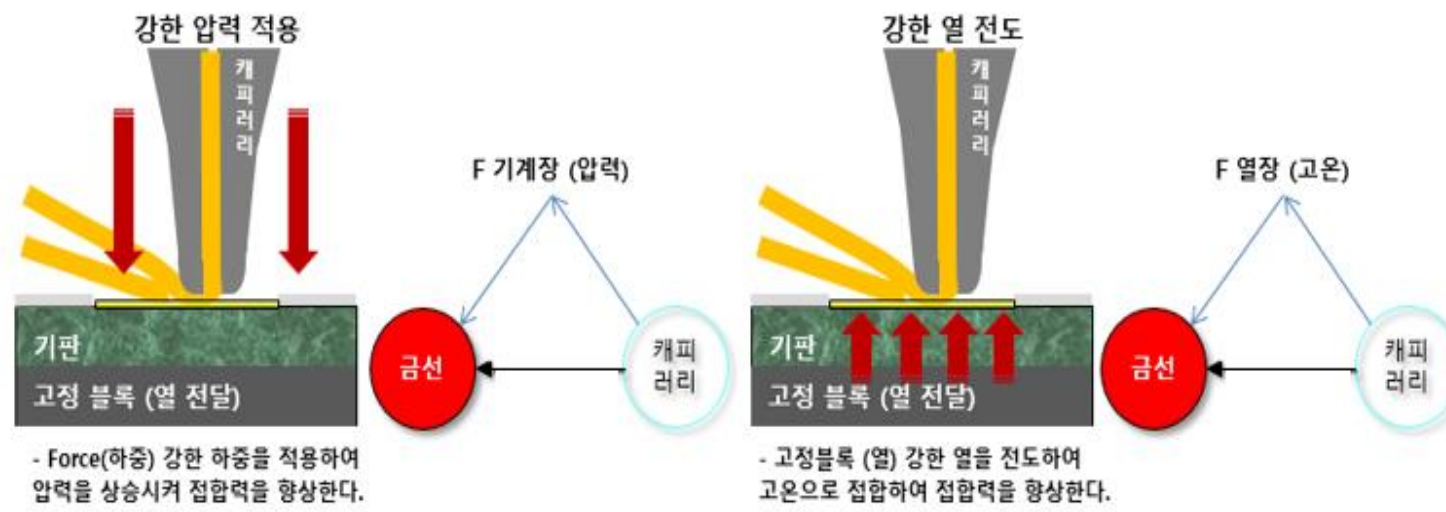

[그림 10] 표준해 물질-장 아이디어 도출

[Fig. 10] Derivation of Standard Solution Matter-Field Ideas

\section{2 최종 해결안 도출}

IFR인 이상적 해결안과 물질-장 분석을 통하여 기계장을 통한 강한 압력을 추가하여 접합력을 향상하는 아이디어와 열 장을 추가하여 높은 열을 전도 시켜 접합력을 향상하는 두 가지 아이디어를 도출하였다. 또한 모순을 이용한 X축에서는 Stitch 간격을 좁게 하고 Y축에서는 Stitch 간격을 높게 한다는 아이디어를 확인하였다. 도출된 모든 아이디어를 종합하여 가장 실행 가능성이 높은 최종 해결안 도출을 위한 아이디어 평가를 진행하였다. 평가 결과 문제 해결에 가장 경제적이고 적용 가능성이 높은 아이디어와 다른 추가적인 문제를 효과적으로 최소화 할 수 있는 최종 해결안은 모순을 해결한 아이디어인 $\mathrm{X}$ 축에서는 Stitch 간격을 좁게 하고 $\mathrm{Y}$ 축에서는 Stitch 간격을 높게 하는 것을 채택하였다[그림 11].

\begin{tabular}{|c|c|c|c|}
\hline 아이디어 & 아이디어 설명 & 예상 결과 & 2차 문제 \\
\hline 강한 압력을 추가 & $\begin{array}{l}\text { 압력의 강도를 높여 } \\
\text { 접합 한다. }\end{array}$ & -. 강한 압력으로 칩 패드 손상 발생 예상 & 품질 문제 발생 예상 \\
\hline 높은 열을 전도 & $\begin{array}{c}\text { 높은 열을 전도하여 } \\
\text { 접합 한다. }\end{array}$ & -. 높은 열로 인해 Ball 흔들림 발생 예상 & 품질 문제 발생 예상 \\
\hline Bump Bond 추가 & $\begin{array}{l}\text { Bump 활용하여 X축으로는 짧 } \\
\text { 게 Z숙로는 높게 만든다 }\end{array}$ & $\begin{array}{l}\text {-. Stitch Lifted 개선 호과 있음 } \\
\text { - BPT(柎합력) 값 높음 }\end{array}$ & 없음, 개선 가능 \\
\hline
\end{tabular}

[그림 11] 해결안 평가

[Fig. 11] Evaluate the Solution

\section{3 최종 해결안 평가}

최종 해결안인 $\mathrm{X}$ 축에서는 Stitch 간격을 좁게 하고 $\mathrm{Y}$ 축에서는 Stitch 간격을 높게 한다는 최종 아이디어를 통하여 Bump Bond를 추가하는 품질 평가를 진행하였다. SK 하이닉스(주)의 내부 산업보안 규정에 따라 Bump Size는 표현하지 않았으며, 최적 Bump 
도출을 위한 평가를 진행하였다. 추가되는 Bump Bond를 제외한 설비의 모든 Parameter와 설비는 동일한 조건으로 평가를 진행하였다. (Power, Force, TEMP, Time 고정) Bump Bond 추가에 따른 점검을 작은 사람 모델을 통하여 마이크로 모델로 분석하였으며, 분석 결과 간섭이 없음을 확인하였다[그림 12].

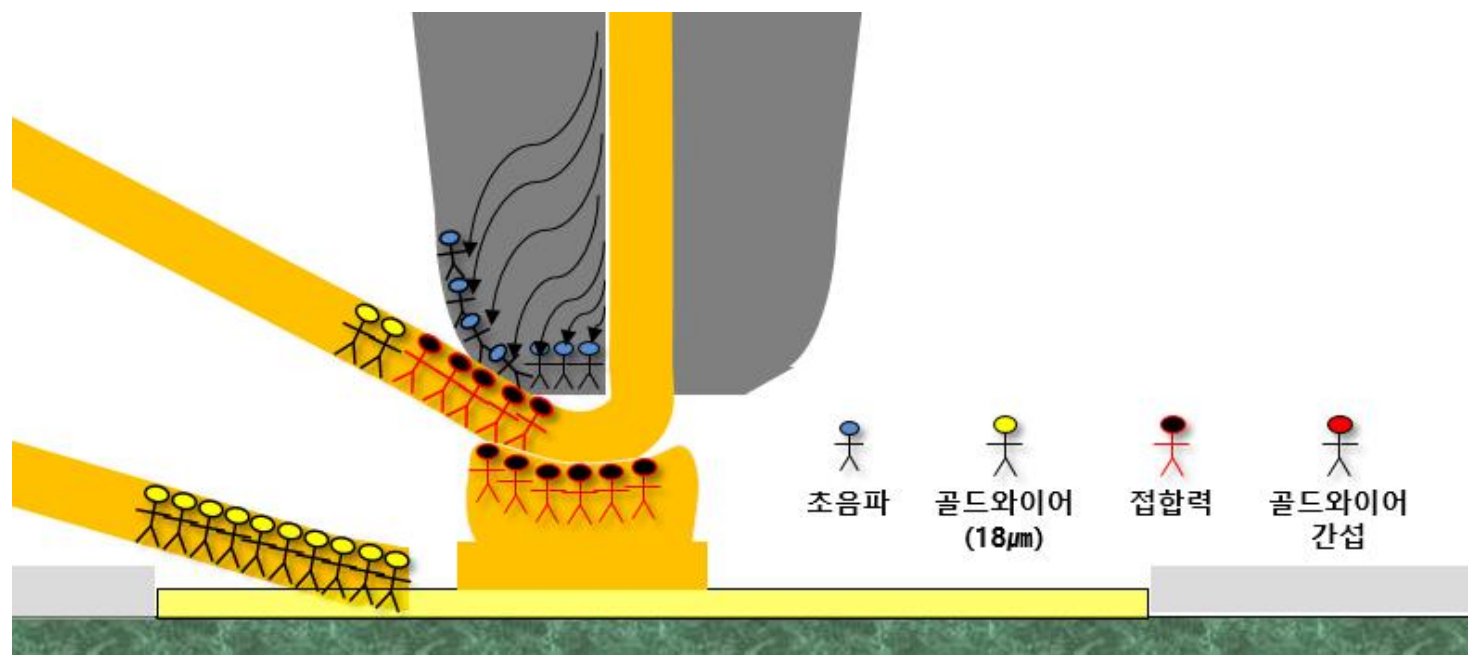

[그림 12] 작은사람 모델 분석

[Fig. 12] Little Person Model Analysis

Wire Bonding 완료 후 BST, BPT, Loop height 관점에서 품질 분석을 하였다. BST 점검 결과 적용 전/후로 P-value 0.05 이상으로 신뢰성 $95 \%$ 기준으로 유의차가 없어 특이사항 없는 것을 확인하였다[그림 13].

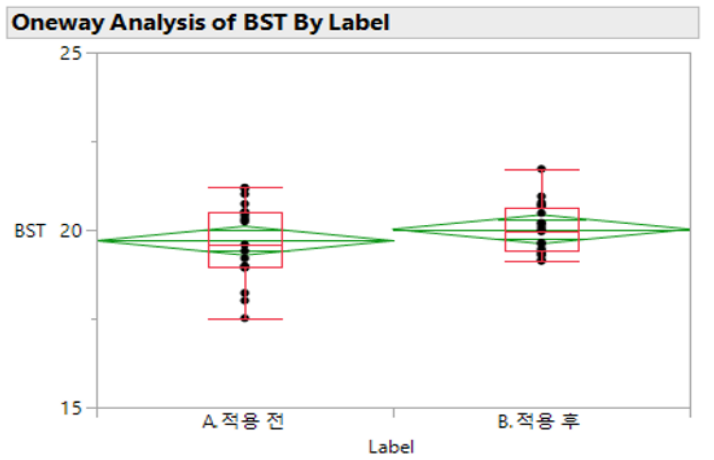

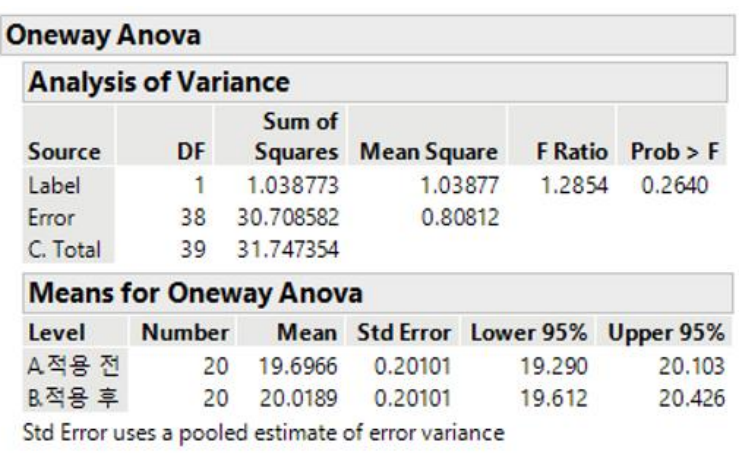

[그림 13] BST 점검결과

Loop height에 대한 점검 결과 적용 전/후로 P-value 0.05 미만의 유의차가 확인되었으나 $\mathrm{Leg}$ 간 차이가 측정 오차인 $1 \mathrm{um}$ 미만인 $0.4 \mathrm{um}$ 로 확인되어 실질적으로 유의차가 있다고 볼 수 없어 특이사항 없는 것을 확인하였다[그림 14]. 


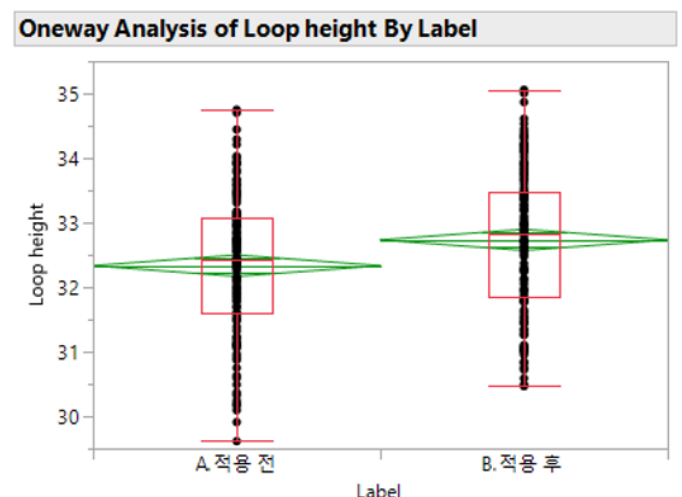

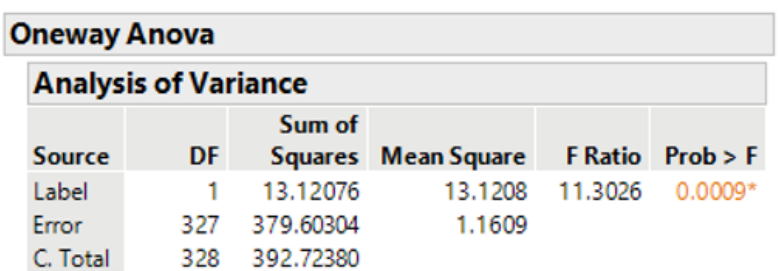

Means for Oneway Anova

\begin{tabular}{l|l|l|l|l}
\hline Level Number & Mean Std Error Lower 95\% & Upper $95 \%$
\end{tabular}

$\begin{array}{llllll}\text { A 적용 전 } & 163 & 32.3341 & 0.08439 & 32.168 & 32.500\end{array}$

$\begin{array}{llllll}\text { B.적용 후 } & 166 & 32.7335 & 0.08363 & 32.569 & 32.898\end{array}$

Std Error uses a pooled estimate of error variance

Excluded Rows 3

[그림 14] Loop Heighe 유의차 분석 결과

[Fig. 14] Loop Heighe Significant Difference Analysis Result

$\mathrm{BPT}$ 점검 결과 적용 전/후로 P-value 0.05 미만으로 약 $2 \mathrm{~g}$ 수준의 증가 유의차가 발생하는 것을 확인하였다. 또한, 적용 전/후로 BPT test mode에 따른 Pearson test 결과 파단 Mode가 Mode 2 에서 Mode 5로 전환됨에 따라 실질적으로 Stitch 부 Bondability에서 $2 \mathrm{~g}$ 이상의 개선 효과가 발생했음을 확인할 수 있었다[그림 15].
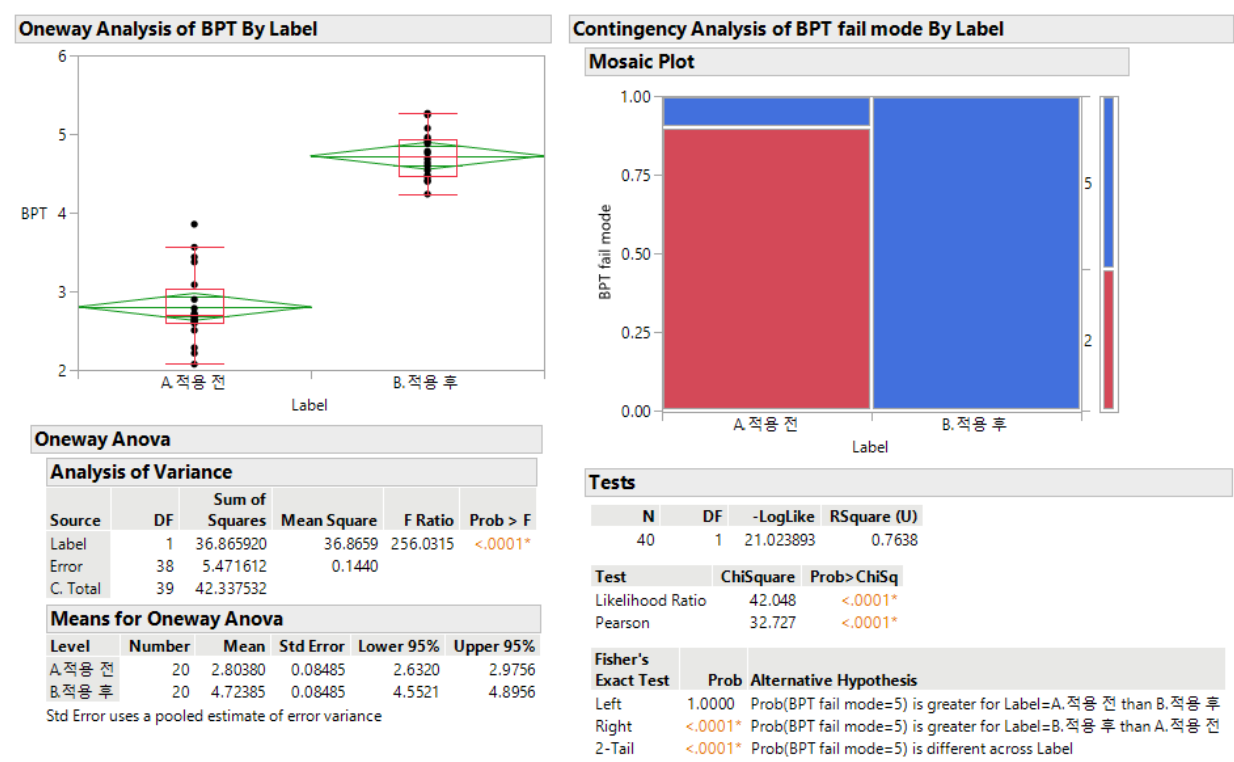

[그림 15] BPT 점검결과 및 Test mode 비교분석 결과

[Fig. 15] BPT Inspection Result and Test Mode Comparative Analysis Result

\section{5. 결론}

본 논문에서는 반도체 Packaging 공정의 와이어 본딩에서 발생하는 문제를 트리즈(TRIZ)창의적 문제 해결이론을 이용해 해결한 사례를 설명하였다. 문제를 체계적으로 분석하여 물리모순을 도출하였으며, 도출된 모순을 일반화하여 내부자원인 골드와이어를 이용한 예비작용 발명원리를 적용하였다. 적용된 예비작용인 Bump Bond의 추가로 인하여 좁은 접합면적에서 접합력 향상을 확인하였으며, 이로 인하여 와이어 
본딩 공정의 품질향상을 확보할 수 있었다. 추가적인 생산성 저하에 대해서는 품질 확보로 인한 개선이 더욱 중요하여 약간의 생산성 저하에 대해서는 다른 방향으로 개선하고자 하였다. 개선을 위한 모든 $\mathrm{Data}$ 는 검증을 통하여 접합력 향상에 신뢰성이 있음을 확인하였다. 문제 해결을 위한 분석기법으로 거시적인 현상을 마이크로 레벨 수준의 작은 사람 모델로 접근하여 체계적인 원인분석을 할 수 있었다. 본 연구에서 보여준 바와 같이 창의적 문제 해결이론 TRIZ는 나노 스케일 첨단 반도체 분야를 비롯한 모든 산업군 특히 반도체 생산 현장에서 발생하는 모든 문제를 체계적으로 분석하여 해결안을 도출할 수 있는 공정혁신의 유용한 도구임이 증명되었다.

\section{6. 감사의 글}

This research was supported by Basic Science Research Program through the National Research Foundation of Korea (NRF) funded by the Ministry of Education (2018R1D1A1B07049244).

\section{References}

[1] Kwanoo Ham, Kwang Soo Kim, A study on the improvement process according to the advancement of semiconductor devices: based on the case of the V-1 BAND improvement process, Proceeding of Korean Society for Quality Management Conference, (2018), May 25; Seoul, Korea.

[2] http://www.samsungsemiconstory.com/2206, Jan 16 (2020)

[3] Oh Ae-sun, Bae Hyun-cheol, Al wire bonding process in the power semiconductor package process, Proceeding of the Institute of Electronics and information Enginners conference, (2017), June 29 - July 1; Busan, Korea.

[4] Oh Ae-sun, Bae Hyeon-cheol, Um Yong-seong, Choi Gwang-seong, Son Ji-hye, Jung Isle, Bond Pull Test analysis using Al Ultrasonic Bonding process, Proceeding of the Institute of Electronics and information Enginners conference, (2016), June 22 -24; Jeju, Korea.

[5] Richard R. Chromik, Dina Goldbaum, J. Michael Shockley, Stephen Yue, Eric Irissou, Jean-Gabriel Legoux, Nicholas $\mathrm{X}$. Randall, Modified ball bond shear test for determination of adhesion strength of cold spray splats, Surface and Coatings Technology, (2010), Vol.205, No.5, pp.1409-1414. DOI:10.1016/j.surfcoat.2010.07.037

[6] Yongwon Song, Kyungmo Kim, Seonghwan Kim, book Creative Problem Solving Theory TRIZ, Korean Standards Association Media, pp.26-33, (2017)

[7] E. K. Kim, B. C. Koo, A Study of Applying TRIZ in Software Development, Journal of the Korea Institute Of Information and Communication Engineering, (2014), Vol.18, No.3, pp.719-726, DOI: 10.6109/jkiice.2014.18.3.719

[8] Yongwon Song, Kyungmo Kim, Seonghwan Kim, book Creative Problem Solving Theory TRIZ, Korean Standards Association Media, (2017), pp.44-57.

[9] Yongwon Song, Kyungmo Kim, Seonghwan Kim, book Creative Problem Solving Theory TRIZ, Korean Standards Association Media, (2017), pp.236-244.

[10] Yongwon Song, Kyungmo Kim, Seonghwan Kim, Books Creative Problem Solving Theory TRIZ, Korean Standards Association Media, (2017), pp.221-224

[11] Kim Mi-hee, Study of Water Cut and Methane Hydrate Formation Problems in Piping by Systematic Analysis of Technical and Physical Contradictions, Pusan National University, Master's Thesis (2014) 